\title{
Return to Golf, Tennis, and Swimming After Elective Cervical Spine Surgery
}

\author{
Alexandra Richards ${ }^{1}$, Andrew Pines ${ }^{2}$, Nicolas C. Rubel ${ }^{2}$, David Mauler ${ }^{2}$, Joseph Farnsworth ${ }^{1}$, Nan Zhang \\ ${ }^{1}$, Naresh P. Patel ${ }^{1}$, Mark Lyons ${ }^{1}$, Matthew Neal ${ }^{1}$ \\ 1. Neurosurgery, Mayo Clinic Hospital, Phoenix, USA 2. Neurosurgery, Mayo Clinic Alix School of Medicine, Scottsdale, \\ USA
}

Corresponding author: Alexandra Richards, lexy.e.richards@gmail.com

\section{Abstract \\ Background}

After surgery for degenerative cervical spine problems, most patients hope to return to non-competitive sports and other leisure activities. Limited data are available to counsel patients about return to play (RTP) in non-competitive sports after cervical surgery.

\section{Methods}

Participants had cervical surgery for degenerative diagnoses from April 1, 2007, to April 1, 2018. Demographic data were collected, and participants were asked to complete a survey regarding sports participation before and after cervical surgery.

\section{Results}

Of the 73 participants who responded to the study, the majority (81.1\%) were able to return to one or multiple hobby sports after elective spine surgery. RTP rates at 12 months for golf, tennis, and swimming were $67.6 \%, 31.2 \%$, and $81.6 \%$, respectively. Younger age and lack of preoperative motor deficit were significant predictors of return to swimming after surgery. After surgery, $54.3 \%$ of golfers reported similar or improved levels of play.

\section{Conclusions}

After elective cervical spine surgery, the majority of hobby athletes can expect to return to athletics. The majority of golfers returned to play with similar or improved frequency and quality of play compared to preoperative levels. Future prospective studies will further elucidate factors predicting RTP after different types of elective cervical surgeries.

Received 08/07/2020

Review began 08/11/2020 Review ended 08/14/2020 Published 08/24/2020

() Copyright 2020 Richards et al. This is an open access article distributed under the terms of the Creative Commons Attribution License CC-BY 4.0., which permits unrestricted use, distribution, and reproduction in any medium, provided the original author and source are credited.
Categories: Physical Medicine \& Rehabilitation, Neurosurgery, Other

Keywords: acdf, cervical fusion, cervical laminectomy, return to play, hobby sports, return to sport

\section{Introduction}

\section{Background/rationale}

Patients undergo cervical spine surgery to address pain and other neurological symptoms. After surgery for degenerative cervical spine problems, most patients hope to return to non-competitive sports and other leisure activities after surgery. Preoperatively, patients frequently ask whether they will be able to return to sporting activities such as golf, tennis, and swimming. Limited data are available to counsel patients about return to play (RTP) in non-competitive sports after cervical surgery. There are general criteria for return to competitive sport play after spine surgery. There is consensus that postsurgical, competitive athletes, in particular those participating in contact or high-velocity sports, should be pain-free, be neurologically intact, have full strength, and have full range of motion prior to returning to competitive play [1-3].

RTP after surgery for single-level cervical pathology has been previously examined. There is strong consensus in the literature, despite robust evidence-based data, that athletes, including professional athletes, may return to high-velocity and collision sports after single-level anterior cervical discectomy and fusion (ACDF) surgery as well as posterior cervical foraminotomies [4-7]. Reinke et al. also presented a series of 46 athletes ranging from professional level to hobby athlete who all resumed preoperative sporting activity after single-level cervical total disk replacement for soft disk herniation with radiculopathy [8].

Two publications specifically address RTP in golfers after spine surgery. In a case series, Shifflett et al. surveyed patients who underwent one- or two-level lumbar fusion surgery [9]. They found that $52 \%$ of patients returned to golf course play within one year from surgery. The majority of golfers returned to 
preoperative performance levels and frequency of play. In another study, Abla et al. surveyed the North America Spine Society members about suggested timing of return to golf after various spinal surgeries [10]. The most common recommended time for return to golf after lumbar laminectomy and lumbar microdiscectomy was four to eight weeks, after ACDF was two to three months, and after lumbar fusion was six months. There is a paucity of literature available for counseling hobby athletes about RTP, particularly for golf, after cervical surgery for degenerative pathologies.

There are several epidemiological studies demonstrating the high frequency of spine injuries, particularly in junior elite athletes, participating in tennis [3,9] and swimming [2,11]. To the authors' knowledge, little is known about RTP rates for swimmers and tennis players after cervical surgeries.

This study addresses knowledge gaps for spine surgeons counseling patients about RTP in non-contact hobby sports such as golf, tennis, and swimming. Limited data are available to counsel postoperative spine patients about returning to golf play. To our knowledge, there are no guides for RTP after multilevel anterior cervical fusions or posterior cervical fusions in any of the above-listed sports. In addition, we are unaware of research addressing RTP specifically for swimmers or tennis players after cervical spine surgery.

\section{Objectives}

The aim of this study was to determine RTP rates and predictors for RTP for hobby athletes after elective cervical spine surgery. This will aid healthcare providers in counseling patients on RTP after elective cervical surgery.

\section{Materials And Methods}

\section{Methods}

In this case series study, we first identified patients who underwent cervical surgery for degenerative diagnosis from April 1, 2007, to April 1, 2018, at Mayo Clinic Hospital, Phoenix, AZ. Participants aged 18 to 89 years were included in the study if they underwent an ACDF, posterior cervical fusion, or cervical laminectomy. Exclusion criteria included patients who underwent cervical surgery for non-degenerative pathologies, neurodegenerative disease, simultaneous anterior/posterior cervical surgery, fusions extending into the thoracic spine or fusions extending above cervical 2, revision surgery related to the same surgery, or multi-level corpectomies.

This study had approval from the Institutional Review Board of Mayo Clinic Hospital. Participants consented with a written consent form after being informed about the risks and benefits of study participation.

In our retrospective review, we identified surgery type and patient characteristics that we hypothesized may have impacted RTP. Table 1 includes these details for all surveyed participants who participated in a sport prior to surgery.

\begin{tabular}{|c|c|c|c|c|}
\hline & \multicolumn{2}{|c|}{$\begin{array}{l}\text { Participants who participated in any sports } \\
\text { before surgery }\end{array}$} & \multirow{2}{*}{$\begin{array}{l}\text { Total } \\
(\mathrm{N}=73)\end{array}$} & \multirow{2}{*}{ Palue } \\
\hline & No $(\mathbf{N}=20)$ & Yes $(N=53)$ & & \\
\hline Age & & & & $0.1038^{1}$ \\
\hline $\mathrm{N}$ (missing) & $20(0)$ & $53(0)$ & $73(0)$ & \\
\hline Mean (SD) & $65.3(14.1)$ & $69.9(9.2)$ & $68.7(10.9)$ & \\
\hline Median (IQR) & $66(56-75)$ & $71(63-76)$ & $69(62-76)$ & \\
\hline Range & $33.0-86.0$ & $49.0-90.0$ & $33.0-90.0$ & \\
\hline Gender, n (\%) & & & & $0.1928^{2}$ \\
\hline Male & $12(60.0 \%)$ & 40 (75.5\%) & $52(71.2 \%)$ & \\
\hline Female & $8(40.0 \%)$ & $13(24.5 \%)$ & $21(28.8 \%)$ & \\
\hline Are you currently working? n (\%) & & & & $0.1464^{2}$ \\
\hline Missing & 2 & 3 & 5 & \\
\hline
\end{tabular}




\section{Cureus}

No

Yes

Have you had more than one cervical spine surgery? n (\%)

Missing

No

Yes

Surgery type, n (\%)

ACDF

Laminectomy

PCDF

Other spine surgery, $\mathrm{n}(\%)$

Missing

No

Yes

Diagnosis of myelopathy, $\mathrm{n}(\%)$

No

Yes

Preoperative sensory deficit, n (\%)

No

Yes

Preoperative motor deficit, $\mathrm{n}(\%)$

No

Yes

Smoker, n (\%)

No

Yes

Diabetic, n (\%)

No

Yes
$10(55.6 \%)$. before surgery
$8(44.4 \%)$

No $(\mathbf{N}=20)$

$13(26.0 \%)$

Yes $(\mathbf{N}=53)$

15 (78.9\%)

$4(21.1 \%)$

$13(65.0 \%)$
$3(15.0 \%)$
$4(20.0 \%)$

1

$11(57.9 \%)$

$8(42.1 \%)$

$8(40.0 \%)$

$12(60.0 \%)$

$11(55.0 \%)$

$9(45.0 \%)$

$13(65.0 \%)$

$7(35.0 \%)$

9 (45.0\%)

11 (55.0\%)

$18(90.0 \%)$

$2(10.0 \%)$

5

40 (83.3\%)

8 (16.7\%)

$33(62.3 \%)$

$9(17.0 \%)$

0

$26(49.1 \%)$

27 (50.9\%)

19 (35.8\%)

34 (64.2\%)

25 (47.2\%)

28 (52.8\%)

26 (49.1\%)

27 (50.9\%)

28 (52.8\%)

25 (47.2\%)

$45(84.9 \%)$

8 (15.1\%)
47 (69.1\%)

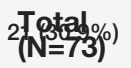

Palue

$0.6730^{2}$

$55(82.1 \%)$

12 (17.9\%)

$0.8674^{3}$

46 (63.0\%)

$14(19.2 \%)$

$13(17.8 \%)$

$0.5084^{2}$

35 (48.6\%)

$0.7432^{2}$

$27(37.0 \%)$

$46(63.0 \%)$

$0.5506^{2}$

$36(49.3 \%)$

$37(50.7 \%)$

$0.2232^{2}$

$39(53.4 \%)$

$34(46.6 \%)$

$0.5506^{2}$

$37(50.7 \%)$

$36(49.3 \%)$

$0.5724^{2}$

$63(86.3 \%)$

10 (13.7\%) 


\section{Cureus}

Cardiac disease/dysfunction, n (\%)

No

Yes
Participants who participated in any sports

before surgery

$17(85.0 \%)$

No $(\mathbf{N}=20)$
$3(15.0 \%)$
$41(77.4 \%)$

Yes $(\mathbf{N}=53)$

$12(22.6 \%)$
$0.4711^{2}$

Palue

\section{TABLE 1: Demographic and Clinical Characteristics}

${ }^{1}$ Equal variance two-sample t-test. ${ }^{2}$ Chi-square $p$-value. ${ }^{3}$ Fisher's exact $p$-value.

ACDF, anterior cervical discectomy and fusion; PCDF, posterior cervical discectomy and fusion

Eligible participants were mailed a survey asking about preoperative participation in the hobby sports of golf, tennis, and swimming. They were also asked about their ability to participate in these activities following their surgery. One month after mailing the envelopes, participants that did not respond were identified. Participants who did not respond received a second mailing with the survey. We did not attempt to contact participants who did not respond after the second survey attempt.

\section{Statistical analysis}

Patients were dichotomized into returning to any of the sports or not based on their survey response. Two sample t-test, Wilcoxon rank-sum test, or Fisher's exact test was used to compare the demographics and clinical characteristics between patients who returned to any of the sports and patients who did not return to identify potential factors that associated with returning to sports.

\section{Results}

We identified 616 cervical procedures performed at our institution from April 4, 2007, April 1, 2018. Of these, 497 patients met our inclusion criteria. We gathered 73 responses to our survey (response rate: 14.7\%). The median age of respondents was 69 years, ranging from 33 to 90 years. Of our respondents, 52 (71.2\%) were males and $21(28.8 \%)$ were females. In terms of procedures performed, 46 (63\%) underwent an ACDF, 14 (19.2\%) underwent a cervical laminectomy, and 13 (17.8\%) underwent a posterior cervical discectomy and fusion. Of the responding patients, 37 (50.7\%) had a preoperative sensory deficit and 34 (46.6\%) had a preoperative motor deficit.

Of the respondents, 53 (72.6\%) played at least one of the three sports on our survey. Overall, 43 (81.1\%) out of 53 of participants who participated in sports before surgery were able to return to their baseline ability. When analyzing the ability of participants to return to playing any of the sports on our survey, we found no significant determining predictors.

Specific to golf, 34 (46.6\%) of responding patients played before surgery. Of these, 23 (67.6\%) were able to return to play. We found no significant determining predictors of this outcome.

Specific to tennis, 16 (21.9\%) of responding patients played before surgery. Of these, 5 (31.2\%) were able to return to play. We found no significant determining predictors of this outcome.

Specific to swimming, 38 (52.1\%) of responding patients swam before surgery. Of these, 31 (81.6\%) were able to return to swimming. We found that both younger age (mean age of 68.2 for those who returned and 77.7 for those who did not return; $\mathrm{p}=0.0109$ ) and the absence of a preoperative motor deficit (100\% patients without preoperative motor deficit returned to swimming, whereas only $69.6 \%$ patients with preoperative motor deficit returned to swimming; $\mathrm{p}=0.0291$ ) were significant determining factors of whether a patient would be able to return to swimming. Table 2 includes descriptive statistics for hobby sports for participants who played hobby sports prior to surgery.

\begin{tabular}{|c|c|c|c|c|c|}
\hline Tennis & $\begin{array}{l}\text { Total } \\
(\mathrm{N}=17)\end{array}$ & Swimming & $\begin{array}{l}\text { Total } \\
(\mathrm{N}=40)\end{array}$ & Golf & $\begin{array}{l}\text { Total } \\
\text { (N=35) }\end{array}$ \\
\hline $\begin{array}{l}\text { Did your spinal problems decrease } \\
\text { the frequency of playing tennis? } n \\
\text { (\%) }\end{array}$ & & $\begin{array}{l}\text { Did your spinal problems } \\
\text { decrease the frequency of } \\
\text { swimming? n (\%) }\end{array}$ & & $\begin{array}{l}\text { Did your spinal problems } \\
\text { decrease the frequency of } \\
\text { playing golf? } n(\%)\end{array}$ & \\
\hline Missing & 2 & Missing & 3 & No & $\begin{array}{l}10 \\
(28.6 \%)\end{array}$ \\
\hline
\end{tabular}




\section{Cureus}

\begin{tabular}{|c|c|c|c|c|c|}
\hline Yennis & $\begin{array}{r}\text { 4T26tä\%) } \\
(\mathrm{N}=17)\end{array}$ & Şwimming & $\begin{array}{l}\text { 20 } \\
\text { (\$Notal } \\
\text { (N) }\end{array}$ & YGsolf & 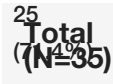 \\
\hline Yes & $\begin{array}{l}11 \\
(73.3 \%)\end{array}$ & Yes & $\begin{array}{l}17 \\
(45.9 \%)\end{array}$ & & \\
\hline $\begin{array}{l}\text { Was your inability to play tennis a } \\
\text { contributing reason for surgery? n } \\
\text { (\%) }\end{array}$ & & $\begin{array}{l}\text { Was your inability to swim a } \\
\text { contributing reason for surgery? } \\
\mathrm{n}(\%)\end{array}$ & & $\begin{array}{l}\text { Was your inability to play golf a } \\
\text { contributing reason for surgery? } \\
n(\%)\end{array}$ & \\
\hline Missing & 2 & Missing & 5 & Missing & 2 \\
\hline No & $\begin{array}{l}10 \\
(66.7 \%)\end{array}$ & No & $\begin{array}{l}26 \\
(74.3 \%)\end{array}$ & No & $\begin{array}{l}18 \\
(54.5 \%)\end{array}$ \\
\hline Yes & $5(33.3 \%)$ & Yes & $9(25.7 \%)$ & Yes & $\begin{array}{l}15 \\
(45.5 \%)\end{array}$ \\
\hline $\begin{array}{l}\text { Frequency of playing tennis after } \\
\text { surgery, } n(\%)\end{array}$ & & $\begin{array}{l}\text { Frequency of swimming after } \\
\text { surgery, } n(\%)\end{array}$ & & $\begin{array}{l}\text { Frequency of playing golf after } \\
\text { surgery, } n(\%)\end{array}$ & \\
\hline Missing & 8 & Missing & 4 & Missing & 7 \\
\hline More & $3(33.3 \%)$ & More & $6(16.7 \%)$ & More & $5(17.9 \%)$ \\
\hline Less & $4(44.4 \%)$ & Less & $\begin{array}{l}14 \\
(38.9 \%)\end{array}$ & Less & $\begin{array}{l}12 \\
(42.9 \%)\end{array}$ \\
\hline Same & $2(22.2 \%)$ & Same & $\begin{array}{l}16 \\
(44.4 \%)\end{array}$ & Same & $\begin{array}{l}11 \\
(39.3 \%)\end{array}$ \\
\hline $\begin{array}{l}\text { Your level of swimming after } \\
\text { surgery, } n \text { (\%) }\end{array}$ & & $\begin{array}{l}\text { Your level of swimming after } \\
\text { surgery, } n(\%)\end{array}$ & & $\begin{array}{l}\text { Your level of playing golf after } \\
\text { surgery, } n(\%)\end{array}$ & \\
\hline Missing & 3 & Missing & 4 & Missing & 6 \\
\hline Higher & $3(21.4 \%)$ & Higher & $8(22.2 \%)$ & Higher & $7(24.1 \%)$ \\
\hline Lower & 6 (42.9\%) & Lower & $\begin{array}{l}11 \\
(30.6 \%)\end{array}$ & Lower & $\begin{array}{l}10 \\
(34.5 \%)\end{array}$ \\
\hline Same & $5(35.7 \%)$ & Same & $\begin{array}{l}17 \\
(47.2 \%)\end{array}$ & Same & $\begin{array}{l}12 \\
(41.4 \%)\end{array}$ \\
\hline $\begin{array}{l}\text { When did you resume playing } \\
\text { tennis after surgery? n (\%) }\end{array}$ & & $\begin{array}{l}\text { When did you resume swimming } \\
\text { after surgery? } \mathrm{n}(\%)\end{array}$ & & $\begin{array}{l}\text { When did you resume playing } \\
\text { golf after surgery? } n(\%)\end{array}$ & \\
\hline Missing & 10 & Missing & 10 & Missing & 10 \\
\hline 3-6 months & 2 (28.6\%) & $<3$ months & $\begin{array}{l}10 \\
(33.3 \%)\end{array}$ & $<3$ months & $6(24.0 \%)$ \\
\hline 6-12 months & $2(28.6 \%)$ & 3-6 months & 9 (30.0\%) & 3-6 months & $5(20.0 \%)$ \\
\hline \multirow[t]{2}{*}{$>12$ months } & $3(42.9 \%)$ & 6-12 months & $8(26.7 \%)$ & 6-12 months & $4(16.0 \%)$ \\
\hline & & & & $>12$ months & $\begin{array}{l}10 \\
(40.0 \%)\end{array}$ \\
\hline
\end{tabular}

TABLE 2: Descriptive Statistics for Hobby Sports for Participants Who Played Hobby Sports Prior to Surgery 
The median age of Americans is increasing [12]. Consequently, healthcare providers will be caring for a growing population of older patients needing cervical surgery for degenerative spine disorders. Many of these patients will participate in sports, as sport participation is one of the most common leisure time physical activities among Americans $[3,13]$. Older adults are motivated to play sports in order to maintain good health, fitness, and joint mobility. Swimming, golf, and tennis are three of the more common sporting activities reported by older adults [14]. The participants in this study represented an older, active patient population with a median age of 69 years and sport participation rate of $72.6 \%$ for swimming, golf, or tennis.

In this cohort, the majority (81.1\%) of athletes who participated in a sport including golf, tennis, or swimming before surgery were able to return to a sport after cervical spine surgery. Of the three sports, swimming and golf had the greatest RTP rates at $81.6 \%$ and $67.6 \%$, respectively. The mean age for tennis players that returned to sport was 63.2 years. This was the lowest mean age compared to the other two sports. We suspect that both of these findings reflect that tennis play requires more dynamic spine movement and impact compared to the other two sports. These characteristics of tennis may favor younger participants and prevent some postoperative patients from returning to play.

Of the three sports, swimming had the greatest percentage of female participants at $21.1 \%$. This is still a small percentage compared to the percentage of male participants. A recent study in England compared male and female participation in hobby sports including swimming. Similar to the findings in this study, males in the English study had a higher rate of sport participation at $41.2 \%$ versus $33.9 \%$ for females [15]. Nonetheless, swimming can be an excellent form of exercise for men and women at all stages of life [1].

Among golfers, cervical pathology prior to surgery did decrease the frequency of sport participation in the majority (71.4\%) of players. The majority of study participants (57.5\%) were able to play after surgery. The players who returned were able to play at the same (39.3\%) or a greater (17.9\%) frequency after surgery. The players who returned were also able to play at the same (41.4\%) or and improved (24.1\%) level of play. Similar findings were noted in the only other known publication examining return to golf after spine surgery. Shifflett et al. reported that $52 \%$ of golfers were able to return to course play within 12 months after a one- or two-level lumbar fusion for degenerative pathologies [9]. In the same study, the authors also found that $80 \%$ of golfers were able to play at the similar or improved handicap. Following elective spine surgery for degenerative cervical and lumbar pathologies, golfers can be expected to return to sport at a high rate with comparable or improved levels of play.

There were several limitations to this study. The cohort size was not large enough for a meaningful analysis of each type of cervical procedure. Therefore, we did not analyze RTP rates for the different cervical procedures. The surveys were performed retrospectively and were subject to recall bias. The survey response rate was only $14.7 \%$, which may be due to outdated contact information as well as using mail for survey collection. If a significant number of the non-responders were able to return to play after surgery, this could significantly change the statistical analysis. Additionally, many of our survey participants identified other hobby sports not initially considered in this study; therefore, future work is needed to examine a greater breadth of hobby sports.

\section{Conclusions}

In this cohort, the majority of hobby athletes were able to return to athletics after elective cervical spine surgery. Among golfers, the frequency and quality of play remained stable or improved postoperatively for the majority of players. Future prospective studies will further elucidate factors predicting RTP after different types of elective cervical surgeries.

\section{Additional Information \\ Disclosures}

Human subjects: Consent was obtained by all participants in this study. Mayo Clinic IRB issued approval 18-002891. The above referenced application is approved by expedited review procedures (45 CFR 46.110, item 5,7 ). This approval is valid for a period of 1 year. The Reviewer conducted a risk-benefit analysis, and determined the study constitutes minimal risk research. The Reviewer determined that this research satisfies the requirements of 45 CFR 46.111. The survey was reviewed and approved as written. The checklist was reviewed and approved with minor edits. The Reviewer noted that oral consent with HIPAA authorization is appropriate for this study. The contact letters were reviewed and approved with minor edits. The written HIPAA form was reviewed and approved with minor edits. The Reviewer approved waiver of the requirement for the Investigator to obtain a signed consent form in accordance with 45 CFR 46.117 as justified by the Investigator. Animal subjects: All authors have confirmed that this study did not involve animal subjects or tissue. Conflicts of interest: In compliance with the ICMJE uniform disclosure form, all authors declare the following: Payment/services info: All authors have declared that no financial support was received from any organization for the submitted work. Financial relationships: All authors have declared that they have no financial relationships at present or within the previous three years with any organizations that might have an interest in the submitted work. Other relationships: All authors have declared that there are no 


\section{References}

1. Huang P, Anissipour A, McGee W, Lemak L: Return-to-play recommendations after cervical, thoracic, and lumbar spine injuries: a comprehensive review. Sports Health. 2016, 8:19-25. 10.1177/1941738115610753

2. Rosenthal BD, Boody BS, Hsu WK: Return to play for athletes. Neurosurg Clin N Am. 2017, 28:163-171. 10.1016/j.nec.2016.08.003

3. Torg JS: Cervical spine injuries and the return to football. Sports Health. 2009, 1:376-383. $10.1177 / 1941738109343161$

4. Kang DG, Anderson JC, Lehman RA Jr: Return to play after cervical disc surgery . Clin Sports Med. 2016, 35:529-543. 10.1016/j.csm.2016.05.001

5. Mai HT, Chun DS, Schneider AD, Hecht AC, Maroon JC, Hsu WK: The difference in clinical outcomes after anterior cervical fusion, disk replacement, and foraminotomy in professional athletes. Clin Spine Surg. 2018, 31:80-84. 10.1097/BSD.0000000000000570

6. Maroon JC, Bost JW, Petraglia AL, et al.: Outcomes after anterior cervical discectomy and fusion in professional athletes. Neurosurgery. 2013, 73:103-112. 10.1227/01.neu.0000429843.68836.91

7. Molinari RW, Pagarigan K, Dettori JR, Molinari R Jr, Dehaven KE: Return to Play in athletes receiving cervical surgery: a systematic review. Global Spine J. 2016, 6:89-96. 10.1055/s-0035-1570460

8. Reinke A, Behr M, Preuss A, Villard J, Meyer B, Ringel F: Return to sports after cervical total disc replacement. World Neurosurg. 2017, 97:241-246. 10.1016/j.wneu.2016.10.042

9. Shifflett GD, Hellman MD, Louie PK, Mikhail C, Park KU, Phillips FM: Return to golf after lumbar fusion . Sports Health. 2017, 9:280-284. 10.1177/1941738116680200

10. Abla AA, Maroon JC, Lochhead R, Sonntag VK, Maroon A, Field M: Return to golf after spine surgery. J Neurosurg Spine. 2011, 14:23-30. 10.3171/2010.9.SPINE10160

11. No authors listed: A sport for all seasons. Swimming has myriad physical and psychological benefits at almost any stage or state of life. Harv Health Lett. 2009, 35:4-5.

12. Cohen SA: A review of demographic and infrastructural factors and potential solutions to the physician and nursing shortage predicted to impact the growing US elderly population. J Public Health Manag Pract. 2009, 15:352-362. 10.1097/PHH.0b013e31819d817d

13. Watson KB, Dai S, Paul P, Carlson SA, Carroll DD, Fulton J: The attributable proportion of specific leisuretime physical activities to total leisure activity volume among US Adults, National Health and Nutrition Examination Survey 1999-2006. J Phys Act Health. 2016, 13:1192-1201. 10.1123/jpah.2015-0695

14. Kolt GS, Driver RP, Giles LC: Why older Australians participate in exercise and sport . J Aging Phys Act. 2004, 12:185-198. 10.1123/japa.12.2.185

15. Stamatakis E, Chaudhury M: Temporal trends in adults' sports participation patterns in England between 1997 and 2006: the Health Survey for England. Br J Sports Med. 2008, 42:901-908. 10.1136/bjsm.2008.048082 